NASA/TM—2007-214994

Concepts for Distributed Engine Control

Dennis E. Culley, Randy Thomas, and Joseph Saus

Glenn Research Center, Cleveland, Ohio 


\section{NASA STI Program . . . in Profile}

Since its founding, NASA has been dedicated to the advancement of aeronautics and space science. The NASA Scientific and Technical Information (STI) program plays a key part in helping NASA maintain this important role.

The NASA STI Program operates under the auspices of the Agency Chief Information Officer. It collects, organizes, provides for archiving, and disseminates NASA's STI. The NASA STI program provides access to the NASA Aeronautics and Space Database and its public interface, the NASA Technical Reports Server, thus providing one of the largest collections of aeronautical and space science STI in the world. Results are published in both non-NASA channels and by NASA in the NASA STI Report Series, which includes the following report types:

- TECHNICAL PUBLICATION. Reports of completed research or a major significant phase of research that present the results of NASA programs and include extensive data or theoretical analysis. Includes compilations of significant scientific and technical data and information deemed to be of continuing reference value. NASA counterpart of peer-reviewed formal professional papers but has less stringent limitations on manuscript length and extent of graphic presentations.

- TECHNICAL MEMORANDUM. Scientific and technical findings that are preliminary or of specialized interest, e.g., quick release reports, working papers, and bibliographies that contain minimal annotation. Does not contain extensive analysis.

- CONTRACTOR REPORT. Scientific and technical findings by NASA-sponsored contractors and grantees.
- CONFERENCE PUBLICATION. Collected papers from scientific and technical conferences, symposia, seminars, or other meetings sponsored or cosponsored by NASA.

- SPECIAL PUBLICATION. Scientific, technical, or historical information from NASA programs, projects, and missions, often concerned with subjects having substantial public interest.

- TECHNICAL TRANSLATION. Englishlanguage translations of foreign scientific and technical material pertinent to NASA's mission.

Specialized services also include creating custom thesauri, building customized databases, organizing and publishing research results.

For more information about the NASA STI program, see the following:

- Access the NASA STI program home page at http://www.sti.nasa.gov

- E-mail your question via the Internet to help@sti.nasa.gov

- Fax your question to the NASA STI Help Desk at 301-621-0134

- Telephone the NASA STI Help Desk at 301-621-0390

- Write to: NASA Center for AeroSpace Information (CASI) 7115 Standard Drive Hanover, MD 21076-1320 


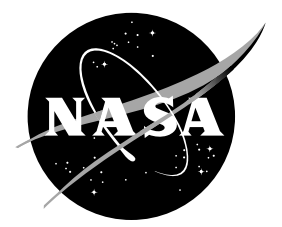

\section{Concepts for Distributed Engine Control}

Dennis E. Culley, Randy Thomas, and Joseph Saus

Glenn Research Center, Cleveland, Ohio

Prepared for the

43rd Joint Propulsion Conference and Exhibit

cosponsored by the AIAA, ASME, SAE, and ASEE

Cincinnati, Ohio, July 8-11, 2007

National Aeronautics and

Space Administration

Glenn Research Center

Cleveland, Ohio 44135 
This work was sponsored by the Fundamental Aeronautics Program at the NASA Glenn Research Center.

Level of Review: This material has been technically reviewed by technical management.

Available from

NASA Center for Aerospace Information

7115 Standard Drive

Hanover, MD 21076-1320
National Technical Information Service 5285 Port Royal Road Springfield, VA 22161

Available electronically at http://gltrs.grc.nasa.gov 


\title{
Concepts for Distributed Engine Control
}

\author{
Dennis E. Culley, Randy Thomas, and Joseph Saus \\ National Aeronautics and Space Administration \\ Glenn Research Center \\ Cleveland, Ohio 44135
}

\begin{abstract}
Gas turbine engines for aero-propulsion systems are found to be highly optimized machines after over 70 years of development. Still, additional performance improvements are sought while reduction in the overall cost is increasingly a driving factor. Control systems play a vitally important part in these metrics but are severely constrained by the operating environment and the consequences of system failure. The considerable challenges facing future engine control system design have been investigated. A preliminary analysis has been conducted of the potential benefits of distributed control architecture when applied to aero-engines. In particular, reductions in size, weight, and cost of the control system are possible. NASA is conducting research to further explore these benefits, with emphasis on the particular benefits enabled by high temperature electronics and an open-systems approach to standardized communications interfaces.
\end{abstract}

\section{Introduction}

The history of the turbine engine has largely been one of mechanical innovation. Huge strides over the past 70 years in aerothermodynamics and material development have improved engine performance and efficiency to an unprecedented degree. Control systems, although critical to the engine operation, have largely been designed to implement engine functionality rather than be a driving force behind their performance. This has been a result of the natural incremental progression of technology which has seen controls evolve from complex mechanisms to the present day Full Authority Digital Engine Control (FADEC). In contrast, the future of the aero-engine is destined to be an increasingly multidisciplinary endeavor, in which control systems will take a leading role.

From the late 1980's into 2003 a research program, known as the Integrated High Performance Turbine Engine Technology (IHPTET) initiative, was jointly conducted by the United States Army, Air Force, Navy, NASA, and the Defense Advanced Research Projects Agency (DARPA). Two of the specific goals of this program, among others, were to double turbine engine power-to-weight ratio while reducing production and maintenance costs on the order of $35 \%$. In a study by Lewis ${ }^{1}$ a compelling case was made that the engine control system is both a major factor in achieving future propulsion system goals and also a major constraint in their realization. While recounting past progress in aero engine technology, Ballal and Zelina ${ }^{2}$ described how future engine performance enhancements will be made, emphasizing the increasing role of control systems. Tong ${ }^{3}$ provides a system analysis of the most promising intelligent engine technologies which enable the engine to adapt to changing operating conditions. Key to all of these improvements will be the significant expansion of engine control responsibilities. The question of how engine control systems can expand in scope yet lower their impact on system cost and weight is a significant challenge to be met.

Similar challenges have been posed in the past. Jaw and Garg ${ }^{4}$ provided insight into how previous control system designers have responded to the challenge and how new technology has been accepted in a risk averse environment. Four phases are described in which the philosophy of control system design has been significantly altered. These are the Start-up Phase, Growth Phase, Electronic Phase, and the Integration Phase. The progress has never been rapid or easy because the application of any new technology is always very carefully considered in light of a highly constrained system with respect to environmental conditions and failure effects.

Presently, in applications like industrial process control, there is what amounts to a revolution in control system design methodology and implementation. This revolution is a direct outgrowth of the dramatic progress in electronics and the use of open system standards in the development of new products and systems. In most process control applications an engineer can choose from a variety of commercially available networked sensors and actuators and integrate those devices with a PC-based control system. Furthermore, using off-the-shelf software, that same engineer can design a highly customized process control system using graphical design tools. The result is a high performance system, assembled at very low cost, in a very short period of time. To assume that the same 
philosophy could be applied to aero-propulsion control systems in the immediate future would be naive. However, the aeronautics industry could certainly learn to adapt new technology, as it has in the past.

The transition to a new engine control system architecture, from centralized control, to one based on the open system standard philosophy, better known as distributed control, can be considered the beginning of a new phase of engine control development. In this paper we would like to discuss the concept of distributed engine control, the impact of engine system challenges and barriers, and how distributed control can positively affect aero-engine systems in terms of performance, weight, and overall cost of ownership.

\section{The Engine Control System 'Problem'}

In early aviation history, ${ }^{4}$ engine control was based on a single hydro-mechanical governor for fuel metering. As engine technology improved, additional controls were added to enable actuation for variable geometry. Each additional control improved engine performance, but eventually the hydro-mechanical controls became so large, heavy and expensive that they became impractical for engine applications. During the 1970 's, as solid state electronics were advancing rapidly, analog and digital circuits came into use for high level supervisory control, trim, and other non-critical functions. Reliability was an issue which prevented their use in mission critical functions but the advantages of using electronics were, in almost every other aspect, readily apparent and their use steadily grew.

As the flexibility and accuracy of digital electronics overtook their analog counterparts the impact of electronic controls progressed from performance improvement and weight reduction to being able to reduce the cycle time for engine modification and development. The relative simplicity of software modification to the control system was the key. Eventually the use of Full Authority Digital Engine Control (FADEC) became the norm for engine control systems. This was only possible, however, by protecting critical electronics in an environmentally-hardened enginemounted enclosure, for reasons which are explained later. The result was a centralized control system architecture with system sensors and actuators operated through an engine-mounted FADEC in close proximity.

The centralized architecture driven by a digital controller has proven to be quite successful; however there are several issues which have become of increasingly greater concern. New engine performance technologies are dependent on adaptive control which significantly increases the burden on a FADEC. This increasing burden can very easily represent a considerable proportion of the available processing power of the FADEC and its impact must be fully assessed. The present implementation of a control system accounts for about 15 to $20 \%$ of the total weight and acquisition cost of an engine ${ }^{1}$. As the need for additional control capability increases, its weight and cost will logically increase in a corresponding fashion. This trend is in opposition to new material and aerothermodynamic technologies which tend to decrease weight, rendering the control system a far greater proportion of total engine weight. Finally, the practice of designing and developing highly customized engine controls has led to a cost burden, not only for acquisition, but for obsolescence, maintenance, and logistics as well. Just as in the 1970's, when hydromechanical controls outgrew their capabilities due to weight and expense, the same may be true today for centralized digital electronic controllers.

There are three areas where future engine control systems will have the greatest benefit. These are i) total engine weight reduction; ii) increased engine performance, including the enabling of new technologies for engine performance gain; and iii) lower overall cost of ownership. The best opportunity to achieve these benefits, while satisfying all the related control system and engine constraints, will be by rethinking the implementation of engine control systems and migrating from the centralized control architecture to a distributed control architecture based on open systems standards.

\section{What is Distributed Control Architecture?}

The most basic question to ask is: What are the distinguishing features of distributed control?

In the most simple of terms, a control system is a collection of tasks which must be accomplished in coordination with one another to achieve a particular goal. What most distinguishes centralized control system architecture from Distributed Control System (DCS) architecture is the spatial construction of its processes. For a given control system to work, all the same tasks must be accomplished regardless of the architecture. In that sense control system architecture can be viewed as a locus of (design) points. At one end of this spectrum is centralized control, in which all information processing, that is, data manipulation and decision making, is made in one location. This is shown graphically in Figure 1. Distributed Control, quite simply, is everything else. While this presents endless variations it also adds a level of confusion about what is the 'best' architecture. One possible depiction of Distributed Control is shown in Figure 2. 


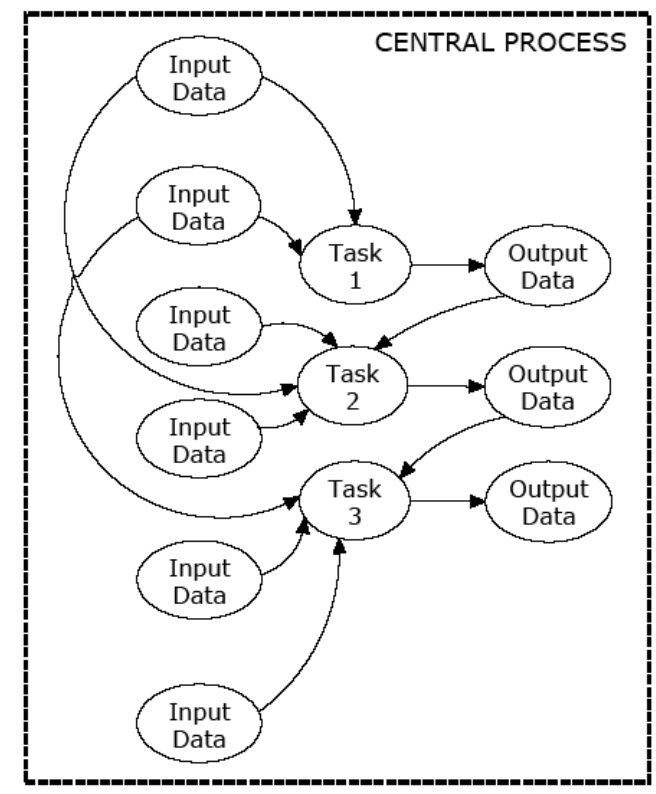

Figure 1.-Centralized Control Process. Each task shares processing time. Data flow is controlled within the process.

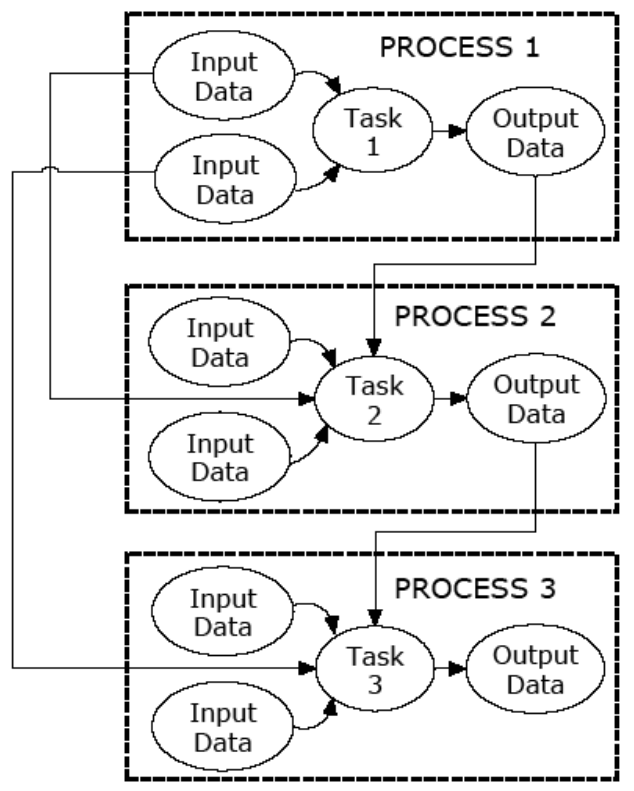

Figure 2.-Distributed Control Process. Each task is run independently and simultaneously. Data flow must be carefully coordinated between processes.

Control systems, however, do not consist of just information processing elements. They must have one, or more sensors and one, or more, actuators to be complete and therefore useful. Sensors create data from the external environment for the control system to process. Actuators act upon the external environment using data which was processed by the control system. When dealing with real-world systems, where data is acquired (sensor location) and where the process is manipulated (actuator location) is not arbitrary. In contrast, where data processing (or decision making) occurs is almost completely arbitrary. Under distributed control, processing should be performed where it is most beneficial to the goals of the overall system.

With this understanding, the control system can be considered as an abstraction in which data enters, is combined and manipulated for some useful purpose, and is then released back into the environment which is subsequently altered. The process is then endlessly repeated. The rate at which this occurs is a critical parameter which affects the ability of the control system to function effectively. In the context of a distributed control system architecture, the single most important criterion for effective control is data availability. This assumes that each distributed process is not data independent, that is, it requires data from a neighboring process to complete its task.

There are, in fact, very few systems which can be classified as purely 'centralized.' For example, many sensors perform some processing, albeit in the analog domain, to linearize the data. While a linearized transducer is not typically considered to be a distributed system element, it does in fact relieve some of the burden from a control rule processor. In order to most effectively share information between processes, however, the data must be available in a format which is consistent and unambiguous. Standardized data is also data which requires the least amount of manipulation by the receiving process in order to be used.

The characteristics of distributed control are those in which;

- Processing is performed at the location which is most beneficial for the overall system goals.

- Information 'flows' throughout the system and is available wherever and whenever it is needed.

- Information is available in a standard format which is unambiguous to the receiving process.

One problem with the distributed system concept, as described above, is the lack of a concrete definition which describes its implementation. This is both a strength and a weakness. It is a strength because it does not limit the possibilities on how a system can be conceived or implemented, but it is also a weakness because this lack of definition can lead to a myriad of components which have no commonality or compatibility with one another. The proper use of standards provides a method which prevents such problems during system development because it 
requires the specification of a common hardware and software interface which interconnects the elements of the system. A notional difference between central and distributed implementation is illustrated in Figure 3 and Figure 4.

The definition of a common interface standard benefits both the decomposition of the system control problem and the integration of its components. Decomposition is the system engineering process of breaking down a large, complex problem into smaller, more manageable pieces. Decomposition identifies the discrete building blocks of the system and completely specifies system elements and their function. These functional elements are completely selfcontained, specifying the required input, the function, and its output. The main benefit of this process is that it enables the parallel and semi-independent development of system components.

The integration process also becomes more efficient assuming the decomposition process was properly completed. Functional elements, which were designed to perform a specific function and which meet the interface, can be inserted into the system with minimal impact on the operation of the larger system. This modular capability can be exploited in many ways because the system element performs as long as the interface requirements are met. When the entire system is designed in this manner any component can be replaced or simulated for purposes such as testing or component upgrade.

Distributed systems don't require common interfaces but the benefits of such an implementation should be obvious. The use of Open Systems Interconnection (OSI) standards is most preferable because it increases participation in the development of the interface beyond an individual engineering project. In other words, any unique or proprietary solution to a problem has limited support because of resource limitations. OSI increases the availability of support hardware and software and leads to better understanding, robustness, and reliability of the system.

\section{Propulsion Engine System Constraints}

Any design problem is bounded by system constraints which represent reality and which govern the conditions in which the system must perform. To propose solutions which violate these conditions is to propose a non-solution. The value of a non-solution may be in identifying an area of research which, if resolved, would enable a viable design. In any case, system constraints must be identified and well understood.

Understanding how constraints impact control system architecture and design provide insight into how the architecture can be used to improve the system metrics. For aero-engine applications the system constraints can be categorized in four areas in order of importance:

A. Failure effects in a mission critical design.

B. Extreme environmental conditions.

C. Performance sensitivity to system weight.

D. Sensitivity to overall cost, including development, manufacture, operation, maintenance, and logistics.

Failure effects and environmental conditions are fixed constraints, that is, they must be satisfied at any cost in order to field an engine system. System weight and overall cost, in contrast, are constraints whose value is largely

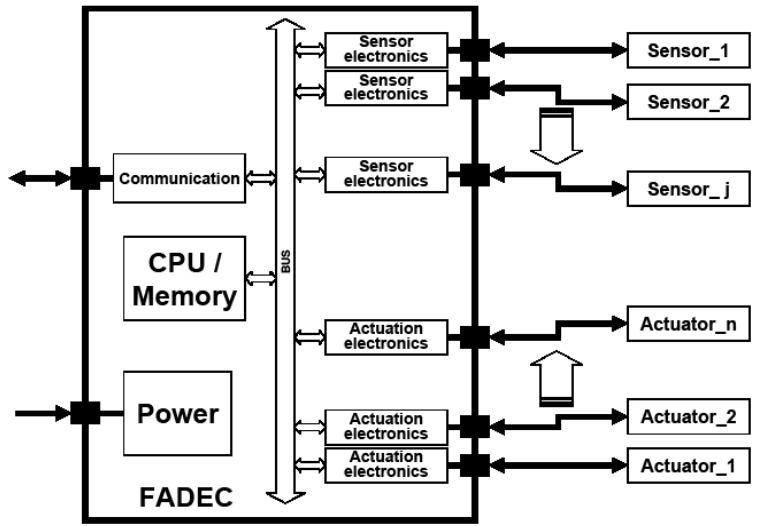

Figure 3.-Notional block diagram of a centralized control architecture. Each function resides within the FADEC and uses unique point-to-point analog connections to system effectors.

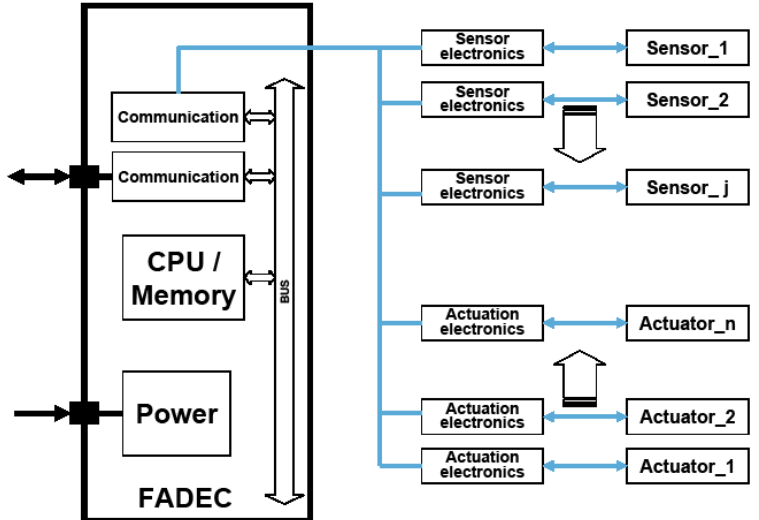

Figure 4.-Notional block diagram of a distributed control architecture. Functions are distributed outside of the FADEC and communicate via a common interface standard. 
determined by business decisions because they impact the ability to sell the engine to end users. There is more leeway in weight and cost constraints, however, they ultimately determine the success of the engine system.

\section{A. Failure Effects}

In an aircraft application the effect of a component failure can be catastrophic for both life and equipment. Obviously, no component, much less complex system, can be created which is $100 \%$ reliable. Failing to a safe state, that is, preventing the failure from propagating throughout the system must be part of the design process. Combining safe failures with redundancy is intended to mitigate the effect of a failure. The consideration of failure effects has a substantial impact on control system weight and cost because high reliability components tend to be more conservative, heavier, and more expensive because of their construction and environmental screening.

\section{B. Environmental Conditions}

Environmental conditions in, on, and around the engine assembly are severe and create a very difficult operating environment for electronic assemblies.

Temperature extremes can range from $-60{ }^{\circ} \mathrm{C}$ at high altitudes to $500{ }^{\circ} \mathrm{C}$ or more near the combustor. In the hot gas path itself temperatures can exceed $1400{ }^{\circ} \mathrm{C}$. These conditions are well beyond the capabilities of common electronics. Temperature cycling is also a major contributor to mechanical failures in electrical systems. Electronic avionic packages are constructed using thermal conduction as the primary means of removing excess heat. This adds weight to electronic assemblies as additional materials and thermal cooling paths must be designed into them. It also adds cost because the vast majority of commercially available hardware is convection cooled and operates over a much narrower range in temperature.

Vibration from rotating parts in the engine and aerodynamic effects on the aircraft can cause fatigue in circuit assemblies and harnesses. Shock loads from landing or blade failure can destroy components if not properly reinforced. Vibration and shock are typically controlled by stiffening the avionics structure to increase resonant modes and using compliant mounts to limit the magnitude of mechanical displacement at the susceptible frequencies. Component dimensions greatly influence the effect of these constraints.

Water, salt spray, hydrocarbon fuels, and cleaning solvents must be prevented from contacting sensitive circuits and materials to prevent corrosion and circuit malfunction. Avionic assemblies and harnesses are designed to be liquid tight and constructed of resistant materials. Metallic materials require the proper surface treatments for protection. Operation at altitude must be considered and accommodated as low air pressure can induce ionization and render circuitry inoperative.

Circuits and components must be shielded for electromagnetic interference, susceptibility and control (EMI/EMC) and lightning. Careful consideration of grounding and shielding is necessary to minimize problems and can impact system performance under different operating conditions. For example, variability in wiring harnesses can introduce noise in one system while an identical engine has no such problems.

\section{Engine Control System Weight}

A primary engine system metric is the thrust-to-weight ratio. This measure is a source of competitive pressure among engine and air frame manufacturers because it directly affects overall vehicle performance. Not surprisingly, there is great incentive to minimize engine weight and this is being accomplished in many areas through advances in materials and aerothermodynamics. Unfortunately, reducing engine weight without a corresponding reduction in control system weight only accentuates the limitations of the control architecture. Both military and commercial aero-engines have shown growth ${ }^{4}$ over time in the number of sensors and actuators used, therefore, more is being asked of the engine control system and its trend is one of increasing complexity and pervasiveness in the engine. In terms of a system constraint, there is a very careful analysis of the benefit of any new engine control functionality versus its impact on other aspects of the engine. Added weight can be a limiting factor preventing the use of new technology for performance gain.

\section{Overall Cost}

Like system weight the overall cost of ownership of an engine is a complicated subject to analyze because the costs occur at different times in the engine life cycle and are borne by different organizations. Acquisition cost is 
perhaps the least difficult to determine and represents the cost of designing, developing, and manufacturing. What are more difficult to assess are the costs associated with maintenance, repair, and logistics because they are less predictable. Acquisition cost can prevent an engine from being put into service and maintenance cost can reduce its useful service life.

\section{Perceived Benefits of Distributed Control Architecture}

The Distributed Control Architecture for aero-engine control is perceived to have benefits for system weight reduction, performance improvement, and overall cost reduction. To date, these benefits have not been publicly quantified to any degree, largely because it involves a complex and detailed system study. In addition, there are technical challenges to be overcome which preclude implementation in production engines. Still, a qualitative assessment is useful to determine technology areas in need of further development and to create a roadmap for that purpose. What follows is a description of the common Centralized Engine Control followed by an assessment of the impact of Distributed Engine Control and related technologies currently being developed.

In a centralized system, the FADEC must be engine mounted for all but small, highly integrated vehicles such as helicopters. This exception exists because the engine control and vehicle control in a helicopter are tightly intertwined which tends to blur the distinction between engine and vehicle control. The main reason for enginemounting is that the control system is designed around individual point-to-point analog communication with each sensor and actuator. Due to the implication of failure effects, hardware redundancy is a requirement which multiplies the impact of this constraint resulting in the number of conductors in the wiring harness often being 500 or more. The ensuing weight of the conductors requires that the wire harness length be minimized.

To achieve minimum wire harness weight, the FADEC would ideally be located at a point on the engine which represents the center of the harness weight distribution. Unfortunately, the closer the FADEC unit is located to the hot section of the engine the more difficult the thermal constraint becomes. Cooling the FADEC using a fuel-cooled cold plate can be used but the weight penalty is obvious.

Regardless of the cooling method, once engine mounted, the FADEC is subject to all of the environmental conditions described in the previous constraints section. To minimize the impact of shock and vibration it is preferable to reduce package dimensions. This is achieved, at great cost, through a high degree of customization of electronic circuits. Still, the number and size of bulkhead mounted connectors on the FADEC package often drives the enclosure dimensions and shape. The only recourse is to increase the stiffness of the package structure by adding metal.

\section{A. The Impact on Weight Reduction}

When evaluating weight, it is useful to understand how changes in architecture affect the three control system component groups consisting of the FADEC, the wiring harness, and system effectors (sensors and actuators). Each component group is affected, either positively or negatively, by the change.

In a centralized control architecture, the role of the FADEC is to perform three top level functions as shown in Figure 5. They are described as:

- Communicating with the airframe controller to receive engine power commands and to communicate engine status back to the airframe controller

- Executing engine control so that performance is optimized at a specified power level and the given operating conditions.

- Evaluating engine health for one or more purposes including; determination of component failure and wear (diagnostics); estimation of engine maintenance (prognostics); and modification of controller parameters to adapt to system performance degradation.

Each of the three main functions is heavily dependent on digital data processing to achieve its purpose. Engine control, on the other hand, is also concerned with acquiring and transmitting data from and to the analog domain in addition to processing the control laws. Therefore, part of the engine control functionality, i.e. signal conditioning and analog-to-digital/digital-to-analog (A/D:D/A) functions, are more intimately tied to specific effectors.

In a Distributed System, all the functions of the FADEC must be included, although they do not have to be performed in one location as with a centralized control architecture. With the objective being weight reduction, the parsing of FADEC functions is undertaken with the specific intention of reducing the number and length of 


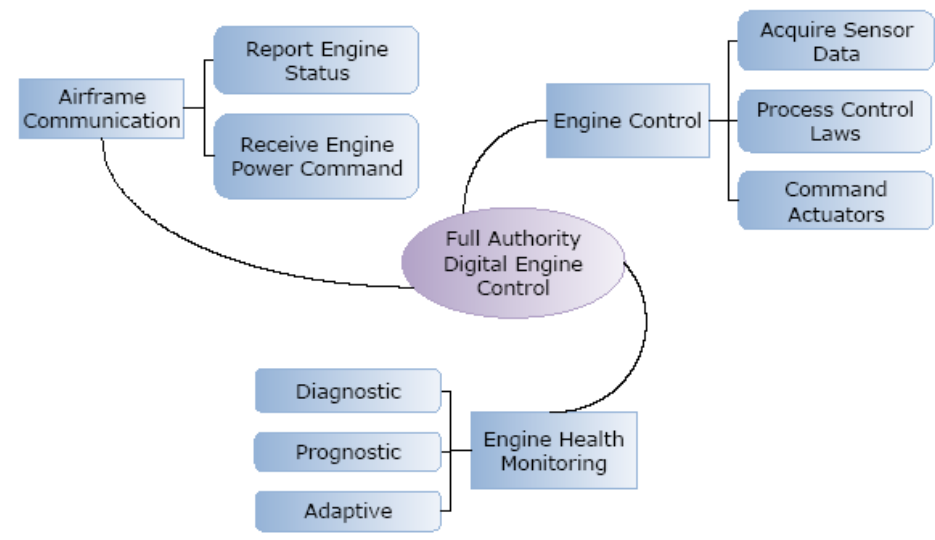

Figure 5.-The primary functions performed by the FADEC under centralized control architecture.

the analog signaling used with a centralized control architecture. There are several connection methods for seria communications such as star, ring, and linear bus structures. Star and ring are depicted in Figure 6 and Figure 7 below. In a study of different connection topologies, Thompson, et al. ${ }^{5}$, concluded that the ring topology minimizes harness weight with maximum reliability.

Under centralized control architecture, approximately $50 \%$ of the circuitry in the FADEC is involved in the processing of analog information. In a distributed system, where all of the communication between system elements is digital, the functionality of the FADEC becomes one of data processing and communications. With no specialized analog circuitry in the FADEC a substantial volume and weight reduction should be expected, perhaps on the order of $50 \%$. This is based on examination of a production FADEC in the $30 \mathrm{k}$ pound thrust class. Whether centralized or distributed, the FADEC would certainly be conduction cooled, implying that the average density of the volume of the avionics enclosure would remain relatively constant. If the volume of the FADEC is reduced by $50 \%$ it could be expected that the weight would be reduced by an equivalent amount. In fact, the FADEC weight may reduce to a greater extent because a $50 \%$ reduction in volume reduces average package dimensions by $20 \%$. This effectively increases the resonant mechanical modes making the FADEC inherently more resistant to shock and vibration, requiring less material in the enclosure for stiffening.

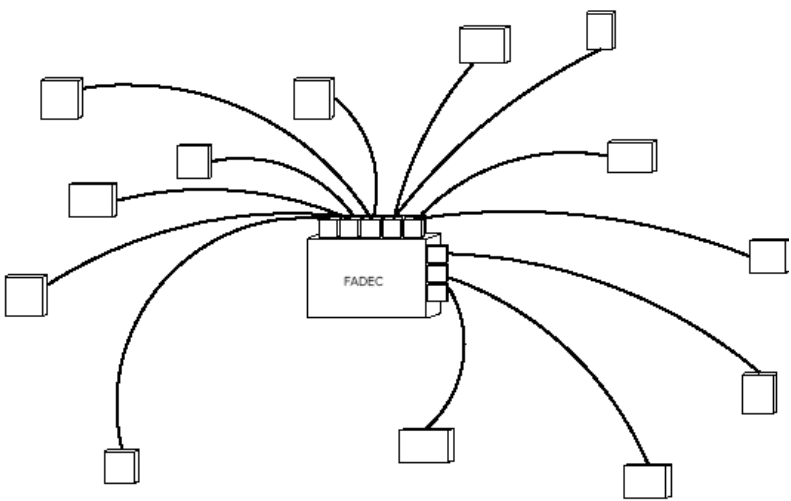

Figure 6.-Serial digital communication used in distributed control requires fewer conductors than its analog counterpart in central control. Using point-topoint connection between the FADEC and system effectors is known as a star configuration. This topology is similar to the connection scheme used in a central control architecture.

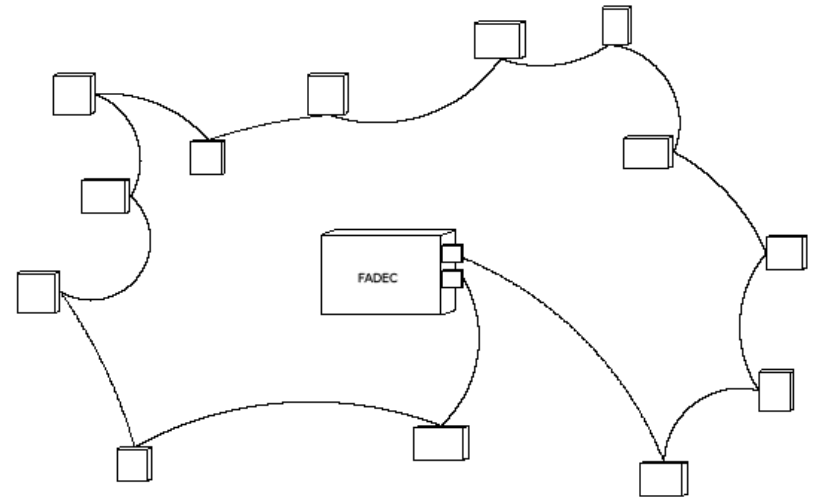

Figure 7.-Distributed control reduces harness weight using shared, serial communications. The ring connection topology may optimize both weight reduction and reliability. 
The above argument assumes the FADEC is engine-mounted. Implementing digital communications removes the restriction for engine-mounting because the harness weight is less of a driver. It is entirely feasible that the FADEC could be mounted in the vehicle where conditions are less hostile, resulting in even more weight reduction. Another alternative could be integration of the engine control with the airframe control.

In contrast, system effectors must increase in weight because they incorporate additional electronic circuitry to operate the device and to communicate over the digital communication medium. This additional weight is difficult to assess because it either requires the use of high temperature electronics or additional cooling for engine mounting.

\section{B. The Impact on Performance Improvement}

The use of Distributed Engine Control is viewed as a mechanism for enhancing engine system performance. Certainly, if weight reduction can be achieved, it will improve system performance. However, there are many other areas affected by distributed control which can count as performance enhancing or enabling. These are sometimes referred to as the-ilities and are somewhat intangible in nature.

Modularity - The preferred basis of Distributed Control lies in the use of open system standards for implementation. What this implies is that the interface between the functional elements of the system are fixed and well defined, such that the exact details of the implementation of the functional element are somewhat irrelevant. Multiple manufacturers, and even different designs, for a single functional element could be installed in the control system without adverse affect. An analogy is made to the installation of a video card in a Personnel Computer. There are a variety of venders which supply video cards, each of which provides equivalent functionality in the computer system. Obsolescence is mitigated by this strategy.

Extensibility - Distributed Control also builds upon modularity to enable new functionality to be installed in the system with minimal impact on existing performance. This argument follows from the concept of functional elements. Functional elements are largely self-contained, that is, they don't rely on, or minimally rely on, other parts of the system to execute their function. Adding new sensors or actuators would not require a change in the FADEC hardware, only software modifications and inclusion on the communications network. In contrast with the centralized architecture, a new engine sensor or actuator would likely require substantial software and hardware modification of the FADEC, making system upgrades or new engine control system design a much more complicated, involved, costly, and lengthy process.

A severe example would be the addition of compressor stability control to an existing engine. This adaptive control technology may require high sensor sampling rates and fast actuation which would require substantial overhaul of a centralized control system. It is possible under centralized control, but most likely would be more difficult, especially as a retrofit. As a distributed control concept, the stability control subsystem could sense and respond to impending stall without direct involvement of the FADEC.

Availability - Engine system availability is impaired by component failures and degradation. Again, the concept of functional elements encourages fault isolation by designing into the component the ability to self-test, selfdiagnose, or even compensate for performance change over time. This tends to isolate component problems to Line Replaceable Units (LRUs) instead of affecting multiple components over large areas of the system. These concepts reduce the time to resolve inevitable component failures resulting in the engine being in-service for a greater percentage of time.

\section{The Impact on Overall Cost Reduction}

Distributed Engine Control is viewed as having a positive affect on reducing overall engine system cost. Overall engine cost can be cast in three categories corresponding to how, where, and when the costs are incurred. These are acquisition cost, operating costs, and maintenance costs.

Acquisition cost is the design, procurement, and integration costs of developing an engine system. As previously described, the preferred implementation of Distributed Control is based on open systems architecture. For any given engine system, the exact same sensors, actuators, and even processing components might not be used. Between engine models or even engine versions, sensors may require different accuracy or be located differently so that they are not interchangeable. The same is true of actuators and processing modules. However, using the open systems approach, the commonality among system components, in terms of meeting the interface standard, enhances component compatibility and the effects can be far reaching.

For example, consider two sensors measuring different parameters on two separate engines using a common distributed architecture. Because they both conform to a common communication interface standard, they are compatible with either engine control system. Even though they may measure different physical parameters and 
have varying degrees of accuracy and range, they still most likely share some common components and software. This brings efficiencies to supply chain manufacturers which eventually lower development costs. The same overlap of compatibility and commonality enhance familiarity for design and integration of new systems, ultimately reducing the cycle time and cost of new system development and increasing the rate of production.

Operating costs are associated with engine performance and are impacted by fuel burn rate and system availability. Again, if distributed control effects an engine weight reduction there is also a reduction in fuel burn. Perhaps more importantly, a high rate of system availability, which seems to be enhanced by distributed control (see previous section), can reduce the number of engine systems needed and the associated costs of delays.

Maintenance costs involve the training of service technicians and the cost of purchasing and maintaining an inventory of spare components. Commonality of system components can reduce the training requirement for maintaining a variety of engine systems. Obsolescence is currently a huge cost burden because it requires the stockpiling of critical components for the life of the engine system. If the component becomes unavailable, a costly development effort must be undertaken to design and qualify a replacement. The use of functional building blocks, advocated by distributed control, reduces the impact of designing and developing replacement components and significantly lowers the need for long term inventory of spare parts.

\section{Technical Challenges for Distributed Engine Control}

The full implementation of Distributed Control in aero-engine applications is predicated on the development of two critical technologies; high temperature electronics, and real-time communications between system elements. Furthermore, these technologies are not mutually exclusive.

\section{A. High Temperature Electronics}

In a centralized engine control architecture the FADEC is typically engine-mounted in order to achieve its weight and performance targets. This highly optimized FADEC uses high performance but conventional silicon electronics in a carefully engineered thermal design to maintain a small, but adequate temperature margin at the silicon junctions of each component. The temperature margin, and the capability of the avionics packaging to maintain this margin, has an impact on component reliability as predicted by Mil-Hdbk-217. It is always the overall packaging design, considering the efficiency of all the thermal pathways from the semiconductor junction to the ambient environment, which determines the maximum operating temperature of the avionics assembly. The maximum operating temperature of the package is typically well below the maximum junction temperature, which for silicon is usually stated as $125^{\circ} \mathrm{C}$. Temperature and its impact on reliability continue to be an active area of research. $^{6}$

The use of Distributed Control has both positive and negative aspects when it comes to temperature constraints. High-end electronics, like high-speed microprocessors, memory, and field programmable components, which are used to perform FADEC functions in a traditional centralized approach, benefit by being relocated to a more benign environment. However, Distributed Control also requires the use of electronics to implement the new functionality, previously performed by the FADEC, within system effectors which must be engine mounted to be physically near to the sensor or actuator. The exact temperature requirement for an effector is dependent upon the mounting location on the engine, but for many devices it will be well above the temperature environment in which silicon electronics can operate. Active cooling or mechanical methods to control temperature adversely affect weight which is one of the primary incentives for the implementation of distributed control. Therefore, the development of high temperature electronics capability is critical for successful distributed control architecture.

A great deal of effort in the development of electronic components for high temperature engine-mounted applications was performed in the 1990's. The use of Silicon on Insulator (SOI), Silicon Carbide, and Gallium Nitride $(\mathrm{GaN})$ for high temperature applications are described by Johnston, et al. ${ }^{7}$ Passive electronics (resistors, capacitors, etc.) also create barriers to implementation at these temperature conditions. ${ }^{8-10}$ Because of the effort by the High Temperature Electronics Consortium (HITEC) there is a limited commercial product line for SOI components, including a microcontroller, static RAM, gate array, crystal clock, and various analog components which operate up to $225{ }^{\circ} \mathrm{C}$. It is projected that Silicon Carbide technology will be capable of operation above $500{ }^{\circ} \mathrm{C}$ although currently it is less mature than SOI. An active SiC program is in effect at NASA Glenn Research Center and is focused on applications in aeronautics. ${ }^{11}$

The current state of the art in high temperature SOI electronics makes at least some sensor and actuator applications in the aero-engine practical. However, without a detailed engineering design it is not clear exactly how 
many engine applications can currently be converted to distributed control. Certainly there will be limitations for advanced control applications which could require substantial processing power.

\section{B. Communications}

In any control system data flow is of paramount importance. In a centralized control system the data flow is coordinated and synchronized by what is essentially a single entity. In contrast, distributed control systems have multiple, independent processes and the coordination and synchronization of data are a much more difficult issue. As described in Section III, the output of any distributed process is based on the quality of the input data which must be both timely and accurate. However, in a broader perspective the communication structure is intimately associated with the interface specification between functional elements. It is a well-defined and consistent interface based on open system standards which gives rise to many of the most important benefits of a distributed control architecture such as modularity, extensibility and availability.

The function of the network itself must have sufficient bandwidth and an appropriate latency to enable closed loop control. At the same time it must be robust enough to accommodate safety and mission critical functions. An evaluation of several existing communication architectures is described by Gwaltny and Briscoe. ${ }^{12}$ However, it may very well be that no existing communication protocol will satisfy the requirements of distributed control for aeroengines. The automotive industry has recently been developing similar control strategies for ground vehicle applications. Several manufacturers have chosen to form a consortium to create their own new communication standard known as FlexRay. ${ }^{13}$

The wiring harness, which is the medium for communications, is the likeliest source of weight reduction. It is worth noting that commercial systems for networking over common household wiring are now available. The potential to use common conductors for both communication and power distribution in an aircraft is of significant interest and has been recently investigated by Jones. ${ }^{14}$

In process control, a 'Smart' device refers to components which provide functions beyond what would be traditionally expected. For a sensor this could include the ability to reconfigure itself for different operating conditions, the ability to recalibrate in-situ, or the ability to communicate over different network protocols. For 'smart' actuators all of the above applies but may also include the ability to close the loop locally in response to a command input. The use of 'smart' devices may be compatible with, but does not wholly define distributed engine control architecture. Still, significant work in industry may be relevant. A recent standard, IEEE-1451, describes a common interface for transducers. ${ }^{15}$ The objective of this standard is to develop a network independent common object module and to enable connection of transducers to network controllers. Part of this functionality includes the embedding of a Transducer Electronic Data Sheet (TEDS) which allows for the connection of any transducer on the network.

Lastly, the development of a communication standard for distributed engine control is not independent of the need for high temperature electronics. While the temperature capability for electronics varies with engine location the need for a consistent communication interface does not. Therefore, the development of a communication standard for aero-engine distributed control may be constrained by the worst-case temperature condition in the engine.

\section{Discussion}

The need to develop and use standard interfaces for distributed engine control cannot be overemphasized. The benefits of a distributed control architecture are beginning to be recognized, understood, and perhaps even quantified by aero-engine manufacturers. The transition to distributed engine control is likely to proceed in the relatively near future regardless of the development of uniform standards. If this occurs independently, the opportunity for additional cost efficiencies due to commonality over a larger pool of engine systems will likely be lost.

Toward that end, the NASA Glenn Research Center has recently organized the Distributed Engine Control Working Group (DECWG). This consortium of government and industry has been established as a forum for the discussion of aero-propulsion systems with a specific emphasis on the future development of engine controls, including both hardware and software, for military and commercial engines. By examining the current and future requirements of propulsion engine systems, the group intends to lay the foundation for a future distributed engine control architecture based upon open system standards.

In all likelihood, the implementation of distributed control will proceed gradually. Engine control functions, beginning with those located on the forward section of the engine, will transition to distributed control as suitable high temperature electronic components are made available. Very high temperature electronics $\left(>225{ }^{\circ} \mathrm{C}\right)$ with 
sufficient capability to perform the required processing functions may not be available for some time. Other alternatives may be useful to consider in the interim. One possibility for sensor functions may be to consider the use of frequency output transducers. This type of device has been used for high temperature applications in the oil well industry. ${ }^{16}$ Using radio frequency (RF) modulation it may even be possible to create a multiplexed sensor network, either wired or wireless, which creates a standardized interface and is compatible with the weight reduction goals described herein. Simple frequency output devices could more reasonably be implemented with $\mathrm{SiC}$ technology in the near future.

\section{Conclusion}

The complex interaction of technology and physical system constraints has produced the Centralized Control System architecture in use on most modern aircraft engines. This architecture is characterized by a centralized, engine-mounted Full Authority Digital Engine Control (FADEC) with numerous point-to-point analog interfaces to the various engine system sensors and actuators. This architecture is shown to result in a complex, constraint driven implementation which may: i) limit the opportunities to reduce control system weight; ii) limit the potential to implement future performance-enhancing technologies; and iii) ultimately drive up overall system cost since cost is the most accommodating constraint in the design process.

The implementation of Distributed Engine Control seeks to overcome the deficiencies inherent in the traditional centralized control system design philosophy by: i) demonstrating potential weight savings, primarily through reducing the number and length of wiring harness conductors; ii) demonstrating high accommodation of new performance-enhancing technology using functional elements connected by open systems interfaces; and iii) potentially high cost savings in all areas including design, manufacturing, integration, operations, maintenance, repair, and logistics.

The technology to implement Distributed Engine Control is still maturing and not completely available at this time. Although detailed engineering designs would be more accurate in assessing the system requirements, it can be stated that additional development of high temperature electronics is necessary, especially in the range of 225 to $500{ }^{\circ} \mathrm{C}$. Also, an appropriate communication technology must be identified which can accommodate the bandwidth and latency requirements for distributed engine control, using electronics which are compatible with the severe thermal environment of the engine.

The Distributed Engine Control Working Group (DECWG) has been established as a forum for the discussion of aero-propulsion systems with a specific emphasis on the future development of engine controls, including both hardware and software, for military and commercial engines. By examining the current and future requirements of propulsion engine systems, the group intends to lay the foundation for a future distributed engine control architecture based upon open system standards, and help define technology development needs.

\section{References}

1. Lewis, T.J., "Distributed Architectures for Advanced Engine Control Systems," AGARD/PEP 86th Symposium on Advanced Aero-Engine Concepts and Controls, Seattle, WA, 1995.

2. Ballal, D.R., Zelina, J., "Progress in Aero Engine Technology (1939-2003)," AIAA-2003-4412, 39th AIAA/ASME/SAE/ ASEE Joint Propulsion Conference and Exhibit, Huntsville, AL, 2003.

3. Tong, M.T., “A Probabilistic Analysis of Intelligent Propulsion System Technologies," Proceeding of GT2007 ASME Turbo Expo, GT2007-27914.

4. Jaw, Link C., Garg, Sanjay, "Propulsion Control Technology Development in the United States: A Historical Perspective," NASA/TM-2005-213978.

5. Thompson, H.A., Chipperfield, A.J., Fleming, P.J., Legge, C., "Distributed Aero-engine Control Systems Architecture Selection Using Multi-objective Optimisation," 1999, Control Engineering Practice, no. 7, pp. 655-664

6. Lall, P., "Tutorial: Temperature as an Input to Microelectronics-Reliability Models," IEEE Transactions on Reliability, vol. 45, issue 1, March 1996, pp. 3-9.

7. Johnston, C., Crossley, A., Sharp, R., "The Possibilities for High Temperature Electronics in Combustion Monitoring," Advanced Sensors and Instrumentation Systems for Combustion Processes (Ref. No. 2000/080) IEE Seminar, 27 June 2000 , pp. 9/1-9/3

8. Grzybowski, R.R., "High Temperature Passive Components for Commercial and Military Applications," Proceedings of the 32nd Intersociety Energy Conversion Engineering Conference, 1997. IECEC-97, Aug. 1997, vol. 1, pp. 699-704.

9. Grzybowski, R.R., "Long Term Behavior of Passive Components for High Temperature Applications-An Update," 1998 Fourth International High Temperature Electronics Conference, 1998 HITEC, pp. 207-214. 
Grzybowski, R.R., "Advances in Electronic Packaging Technologies to Temperatures as High as $500{ }^{\circ} \mathrm{C}$," High-Temperature Electronic Materials, Devices and Sensors Conference, 1998, pp. 207-215.

11. Neudeck, P.G., Okojie, R.S., Chen, L.-Y, "High-Temperature Electronics - A Role for Wide Bandgap Semiconductors?," Proceedings of the IEEE, vol. 90, no. 6, pp. 1065-1076, 2002.

12. Gwaltny, D.A., Briscoe, J.M., "Comparison of Communication Architectures for Spacecraft Modular Avionics Systems," Marshall Space Flight Center, NASA/TM-2006-214431.

13. http://www.flexray.com/, June 1, 2007

14. Jones, C.H., "Communication Over Aircraft Power Lines," 2006 IEEE International Symposium on Power Line Communications and Its Applications, 26-29 March 2006, pp. 149-154.

15. Lee, K.C., Kim, M.H., Lee, S., Lee, H.H., "IEEE-1451-based Smart Module for In-vehicle Networking Systems of Intelligent Vehicles," IEEE Transactions on Industrial Electronics, vol. 51, issue 6, Dec. 2004, pp. 1150-1158.

16. Williams, A., III; Fraenkel, N.R., "Simultaneous Measurement of Pressure, Temperature, and Conductivity with Counters," OCEANS '95. MTS/IEEE. 'Challenges of Our Changing Global Environment'. Conference Proceedings, vol. 1, 9-12 Oct., 1995, pp. 626-630. 


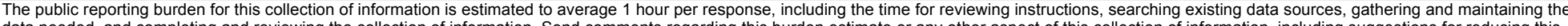

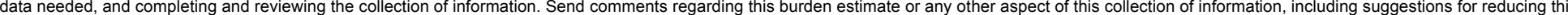

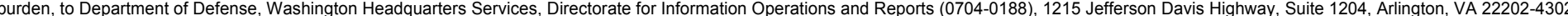

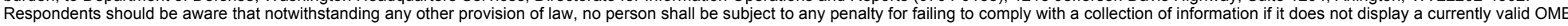
control number.

PLEASE DO NOT RETURN YOUR FORM TO THE ABOVE ADDRESS

\section{REPORT DATE (DD-MM-YYYY) \\ 2. REPORT TYPE \\ 3. DATES COVERED (From - To)}

01-11-2007

Technical Memorandum

\section{TITLE AND SUBTITLE}

Concepts for Distributed Engine Control

5a. CONTRACT NUMBER

5b. GRANT NUMBER

5c. PROGRAM ELEMENT NUMBER

6. AUTHOR(S)

Culley, Dennis, E.; Thomas, Randy; Saus, Joseph

\section{5d. PROJECT NUMBER}

5e. TASK NUMBER

5f. WORK UNIT NUMBER

WBS 561581.02.08.03.17.03

8. PERFORMING ORGANIZATION REPORT NUMBER

E-16194

National Aeronautics and Space Administration

John H. Glenn Research Center at Lewis Field

Cleveland, Ohio 44135-3191

\section{SPONSORING/MONITORING AGENCY NAME(S) AND ADDRESS(ES)}

National Aeronautics and Space Administration

Washington, DC 20546-0001

10. SPONSORING/MONITORS
ACRONYM(S)
NASA
11. SPONSORING/MONITORING
REPORT NUMBER
NASA/TM-2007-214994

\section{DISTRIBUTION/AVAILABILITY STATEMENT}

Unclassified-Unlimited

Subject Categories: 07 and 08

Available electronically at http://gltrs.grc.nasa.gov

This publication is available from the NASA Center for AeroSpace Information, 301-621-0390

\section{SUPPLEMENTARY NOTES}

\section{ABSTRACT}

Gas turbine engines for aero-propulsion systems are found to be highly optimized machines after over 70 years of development. Still, additional performance improvements are sought while reduction in the overall cost is increasingly a driving factor. Control systems play a vitally important part in these metrics but are severely constrained by the operating environment and the consequences of system failure. The considerable challenges facing future engine control system design have been investigated. A preliminary analysis has been conducted of the potential benefits of distributed control architecture when applied to aero-engines. In particular, reductions in size, weight, and cost of the control system are possible. NASA is conducting research to further explore these benefits, with emphasis on the particular benefits enabled by high temperature electronics and an open-systems approach to standardized communications interfaces.

\section{SUBJECT TERMS}

Turbine engine; Propulsion; Control system

\begin{tabular}{|c|c|c|c|c|}
\hline \multicolumn{3}{|c|}{ 16. SECURITY CLASSIFICATION OF: } & \multirow{2}{*}{$\begin{array}{l}\text { 17. LIMITATION OF } \\
\text { ABSTRACT } \\
\text { UU }\end{array}$} & \multirow{2}{*}{$\begin{array}{l}\text { 18. NUMBER } \\
\text { OF } \\
\text { PAGES } \\
18\end{array}$} \\
\hline $\begin{array}{l}\text { a. REPORT } \\
U\end{array}$ & $\begin{array}{l}\text { b. ABSTRACT } \\
\mathrm{U}\end{array}$ & $\begin{array}{l}\text { c. THIS } \\
\text { PAGE } \\
\text { U }\end{array}$ & & \\
\hline
\end{tabular}

\begin{tabular}{l} 
19a. NAME OF RESPONSIBLE PERSON \\
STI Help Desk (email:help@ sti.nasa.gov) \\
\hline 19b. TELEPHONE NUMBER (include area code) \\
301-621-0390
\end{tabular}



